\title{
EDITORIAL
}

\section{Palabras de invitación al XXI Congreso Colombiano de Obstetricia y Ginecología a celebrarse en la ciudad de Santiago de Cali del 23 al 26 de marzo de 1998}

\section{Estimados colegas:}

Reciban una cordial bienvenida a nuestro XXI Congreso Nacional de la especialidad a realizarse en esta querida por todos ciudad de Santiago de Cali donde esperamos pasar unos días muy productivos desde todo punto de vista en la última semana del mes de marzo de 1998.

En esta oportunidad nuestro Congreso Nacional ha sido organizado bajo la dirección de un excelente grupo de personas tanto de la Sociedad Colombiana de Obstetricia y Ginecología S.C.O.G. como de la Sociedad Vallecaucana de Obstetricia y Ginecología SOVOGIN que han confirmado un maravilloso grupo de trabajo ofreciendo uno de los mejores eventos nacionales.

Los Presidentes de las disciplinas afines como Perinatología, Menopausia, Oncología, Endoscopia y Fertilidad-Esterilidad han conformado la base del Comité Científico para poder brindar un evento académico multidisciplinario con quince debates, seis plenarias, quince mesas con expertos, y quince simposios que junto con la presentación de trabajos libres, carteles y videos científicos colmarán seguramente todas sus expectativas.

Tampoco se ha dejado atrás el tratamiento de los temas que sobre el gremio hoy ocupan un lugar supremamente álgido y por esto se cuenta con la capacidad para la realización de cinco debates sobre el tema y una plenaria general.

Además, como siempre, contamos con la valiosa colaboración y patrocinio de la empresa farmacéutica y de tecnología aplicada, las cuales en esta oportunidad estarán participando después de nuestro programa oficial a las 4 de la tarde con una serie de simposios satélites en una modalidad que ha venido haciendo carrera en los congresos internacionales.

Nuestros compañeros del Valle del Cauca nos estarán sorprendiendo con un excepcional programa cultural y social que junto con su tradicional cordialidad y hospitalidad dejarán un gratísimo recuerdo.

Finalmente sean todos bienvenidos y que nuestro congreso les brinde la oportunidad de actualizarse y disfrutar con muchos amigos esta bella ciudad de Cali.

\author{
Jaime Ferro Camargo \\ Presidente S.C.O.G. \\ Presidente XXI Congreso OG 98
}

Santiago de Cali, Septiembre de 1997

El Comité organizador del Vigésimo Primer Congreso Colombiano de Ginecología y Obstetricia y la Junta Directiva Nacional de la Sociedad presentan el contenido preliminar de este Evento que se llevará a cabo entre el 23 y 26 de marzo de 1998 teniendo como sede la ciudad de Cali.

Usted encontrará en este Congreso, un programa muy interesante con temas actuales y perspectivas futuras dentro del área de sus preferencias, por lo que estamos seguros llenarán sus expectativas. Es el congreso 21 para el siglo 21.

Se realizarán Debates, Simposios, Reunión de Expertos, Plenarias, Presentación de Trabajos Libres, Videos, Carteles, etc. en cada una de las disciplinas en que se ha diversificado nuestra especialidad tales como: 
Menopausia, Endoscopia e Infertilidad, Cirugía Ginecológica, Perinatología y Cáncer Ginecológico, buscando un equilibrio tanto en temas de interés, en oportunidad de horarios y en la calidad y prestigio de los Conferencistas.

Igualmente y como es tradicional en los eventos realizados en Cali, vamos a desarrollar interesantes actividades socioculturales y de recreación que no dudamos será de agrado para nuestros visitantes.

En el Valle del Cauca y especialmente en nuestra querida Cali, les daremos la más cálida bienvenida a todos Ustedes con el cariño, espontaneidad, y fraternidad de siempre con la seguridad de que Nuestro Congreso aportará su granito de arena al siglo 21 demostrando que "el Valle del Cauca es un estado de ánimo".

Les invito a que realicemos un Congreso de todos y para todos.

Les esperamos con los brazos abiertos.

María Cecilia Arturo R. Directora Ejecutiva XXI Congreso OG-98

Presidente SOVOGIN 